\title{
A CONTRIBUIÇÃO DA TEORIA DO QUARTO PODER DE SCHÜNEMANN PARA O CONTROLE RACIONAL DE UM SISTEMA PENAL DESLEGITIMADO
}

\author{
Lucas Nogueira Rodrigues da Silva*1 \\ Luiz Fernando Kazmierczak*²
}

\begin{abstract}
Resumo
O presente artigo objetiva analisar de que modo a teoria do quarto poder, desenvolvida por Bernd Schünemann, pode contribuir ao controle racional da realidade operacional deslegitimada do sistema penal brasileiro. Para tanto, analisa-se a incongruência existente entre o discurso e a realidade operacional praticada, impondo-se a construção de um discurso jurídico-penal que busque reduzir a violência real, por meio de critérios racionais. Após verificada a realidade social e acadêmica onde se desenvolveu a referida teoria, constatou-se que a sua incorporação à realidade brasileira exige a aprimoração do ensino e a ciência jurídicas praticadas.
\end{abstract}

Palavras-chave: Teoria do Quarto Poder; Deslegitimação do sistema penal; Dogmática Penal; Controle racional das decisões judiciais; Direito Penal;

\section{THE CONTRIBUTION OF SCHÜNEMANN'S FOURTH POWER'S THEORY FOR A RATIONAL CONTROL OF A DELEGITIMIZED CRIMINAL SYSTEM}

\begin{abstract}
This paper aims to analyze in which way the fourth power's theory, developed by Bernd Schünemann, can contribute to the rational control of the delegitimized operational reality of the Brazil's criminal system. Therefore, it analyzes the existent incongruity between the speech and the operational reality practiced, that imposes the construction of a juristic speech, in criminal mater, that seeks to reduce the real violence, through rational criterions. After veryfying the social and academic's reality from where the referred, theory was developed, it is constatated that its incorporation to the brazilian's reality demands the improvement of law's science and teaching practiced.
\end{abstract}

Keywords: Fourth Power's Theory; Criminal system's delegitimization; Criminal Dogmatic; Judicial decisions' rational control; Criminal Law;

\section{INTRODUÇÃO}

\footnotetext{
${ }^{1}$ Mestrando em Ciência Jurídica pela Universidade Estadual do Norte do Paraná (UENP). Especialista em Direito Penal Econômico pelo IBCCRIM e Universidade de Coimbra. Pós-graduando em Direito Empresarial pela Escola Paulista de Direito (EPD). Graduado em Direito pela Universidade Estadual de Maringá (UEM). Advogado. E-mail: lucasnogueirarsilva@gmail.com

${ }^{2}$ Doutor em Direito Penal pela Pontifícia Universidade Católica de São Paulo (PUC/SP), Mestre em Ciência Jurídica pela Universidade Estadual do Norte do Paraná (UENP) e Graduado em Direito pela Universidade Estadual do Norte do Paraná (UENP) na Faculdade Estadual de Direito do Norte Pioneiro. Professor Adjunto na Universidade Estadual do Norte do Paraná (UENP), na graduação e no Programa de Pós-graduação em Ciência Jurídica (Mestrado). E-mail: $\underline{\text { lfkaz@ uenp.edu.br }}$
} 
O Direito Penal, embasado filosoficamente, por excelência, nas teorias do contrato social, incorporou, no campo de seu discurso, elementos que visam, em abstrato, refrear o poder punitivo exacerbado, dentre os quais se destacam os preceitos da legalidade estrita (taxatividade da lei penal) e da ofensividade a bens jurídicos como requisito indispensável da autorização da sanção penal. Todavia, a despeito do atual estado da arte do discurso jurídicopenal, a realidade operacional dos sistemas penais aparenta caminhar em uma via oposta, pautada por critérios de seletividade dos indivíduos criminalizados, funções ocultas das penas e rótulos infligidos pela atuação do sistema penal, que se demonstram ainda mais latentes em meio à realidade latino-americana.

Diante desse cenário de uma realidade prática que deslegitima os sistemas penais, tomando como marco teórico a obra "Em Busca das Penas Perdidas", publicada pelo autor Eugenio Raúl Zaffaroni em 1989, investiga-se qual seria o papel que incumbe ao discurso jurídico-penal, diante da realidade de crescente violência praticada pelos sistemas penais, que lhes retiraria a legitimidade, e de que modo poderia a ciência jurídica contribuir a uma mudança social desse estado de coisas.

Observadas as premissas trilhadas por Zaffaroni, será analisada a teoria do "quarto poder", que incumbiria à dogmática desempenhada pelos cientistas jurídicos, a qual foi concebida por Bernd Schünemann, festejado professor alemão, pela primeira vez no ano de 2001, e que se tornou mais acessível à realidade brasileira em obra traduzida para o português e publicada em 2018 em território nacional. Mediante estudo das premissas da teoria, também complementadas por Luís Greco, em obra traduzida publicada no Brasil em 2019, é que se busca estabelecer um diálogo entre as ideias de ambos com aquilo que Zaffaroni projetava como sendo o papel da ciência penal, diante da violenta realidade dos sistemas penais na américa latina.

Por fim, por se tratar de teoria concebida em meio à realidade social alemã, para evitar que se fomente o seu transplante acrítico à realidade brasileira, são identificados os fatores conjunturais locais de onde a teoria foi gestada, para que se busque aferir quais seriam os desafios a serem enfrentados, caso se obstine a sua aplicação efetiva em meio à realidade brasileira. 
Justifica-se a pesquisa pelas contribuições que pode proporcionar à prática penal, com a atribuição de uma função à ciência jurídica que possa de fato influir dentro de decisões judiciais, na busca de reduzir os danos advindos de um sistema penal que se demonstrar disfuncional aos seus fins erigidos.

Para atingir o objetivo do estudo, foi empregado o método hipotético-dedutivo, além dos meios de pesquisa eletrônico, documental e bibliográficos. As pesquisas se deram por meio de doutrinas gerais e específicas sobre o assunto, bem como artigos científicos e leituras complementares.

\section{AS MAZELAS SOCIAIS E A DESLEGITIMAÇÃO DO DISCURSO JURÍDICO PENAL ABSTRAÍDO DA REALIDE DAS PRÁTICAS PENAIS}

\subsection{Recorte de Preceitos Garantistas do Discurso Jurídico-Penal}

O discurso jurídico-penal, que fundamenta o arcabouço teórico sobre o qual está estruturado o sistema penal, atribui a este um papel de instrumento de controle social (KAZMIERCZAK, online), de modo que busca seu embasamento filosófico na concepção de contrato social, onde os malfeitores, ao atacarem o direito social, se converteriam em rebeldes e traidores da pátria e deixariam de ser considerados membros da mesma, ao violarem suas leis. $^{3}$

Como decorrência da natureza preponderantemente contratualista que estrutura o direito penal, sobressai a importância, ao discurso jurídico-penal, da observância à lei de forma estrita, em virtude do consentimento original externado pelos membros, quando da adesão ao corpo social (WALDRON, 2003. p. 169). Referido preceito, nos modernos contornos do discurso jurídico-penal, imporia a necessidade de clareza na descrição legislativa de condutas e das sanções, que seja precisa e cognoscível, delimitando o subjetivismo dos

\footnotetext{
${ }^{3}$ ROUSSEAU, Jean Jacques. The social contract \& Discourses by Jean Jean Jacques Rousseau. Book II, Chapter V. The Right of Life and Death. Trad.: COLE, G. D. H. - p. 35. Disponível em:

http://www.dominiopublico.gov.br/pesquisa/PesquisaObraForm.jsp. Acesso em 11 abr. 2020. A tônica empregada por Rousseau nesse trecho, demonstrando extrema defesa do ideário contrato social, podendo até mesmo autorizar a morte dos infratores, seria muitos anos depois utilizado como fundamento à teoria do direito penal do inimigo, conforme: MARTÍN, Luiz Gracia. O Horizonte do Finalismo e o Direito Penal do Inimigo. Tradução: Érika Mendes de Carvalho e Luiz Regis Prado. São Paulo: Editora Revista dos Tribunais, 2007 - p. 98.
} 
operadores jurídicos, e notadamente dos órgãos jurisdicionais (GIACOMOLLI, 2000. p. 98), e impondo a todos, teoricamente, a necessidade de observância rigorosa aos predicados legais.

Tendo a legalidade estrita como sua espinha dorsal, cumulada a outros notórios princípios reitores, o discurso jurídico-penal majoritário, de forma majoritária encampa a posição de que a função primordial do Direito Penal seria o de fornecer proteção aos bens jurídico-penais a tutela necessária. O bem jurídico consistiria em uma concepção surgida dentro de parâmetros constitucionais e seria hábil a impor uma "certa e necessária direção restritiva ao legislador ordinário, quando da criação do injusto penal” (PRADO, 2003. p. 92).

E na tutela penal dos bens jurídicos reconhecidos por uma dada sociedade, considerando se tratar o Direito Penal do meio mais gravoso do ordenamento jurídico para fins sancionatórios, se sustenta, ainda, no campo do discurso jurídico-penal, a defesa do preceito de intervenção mínima, onde a criminalização apenas se justificaria quando se tratar do único e último recurso disponível à tutela deste valor, cabendo ao sistema penal apenas atuar em hipótese extremadas, atento aos preceitos de fragmentariedade e de subsidiariedade (ROCHA, 2018. p. 40).

Ocorre, todavia, que mesmo provendo um recorte garantista de alguns princípios presentes no discurso jurídico-penal, especialmente em campo acadêmico, não se pode perder de vista que o discurso nessa seara, pelas suas características formais, normativas e abstraídas da realidade, se vincula a representações ideais da mesma, utilizando-se de critérios axiológicos (SHECARIA, 2014. p. 42-43). Com isso, não são necessários maiores esforços para constatação de um imenso abismo entre o plano abstrato do discurso jurídico-penal e a realidade das práticas penais, especialmente em nossa região marginal.

\subsection{A Deslegitimação do Sistema Penal antes aos fatores reais de sua aplicação}

A dita operacionalidade real dos sistemas penais em muito do diverge do discurso jurídico-penal, mesmo com os relevantes esforços em refrear o avanço do poder punitivo sobre o indivíduo, com a construção de axiomas garantistas (FERRAJOLI, 2002. p. 74-75) e a defesa pela limitação constitucional da atuação o sistema penal (FELDENS, 2012. p. 65), onde funcionariam os direitos fundamentais como meios de impedir a indevida invasão de espaços de liberdade garantidos pelo texto das constituições. 
Os dramas da realidade operacional do sistema penal e o seu descompasso com o discurso jurídico-penal já há muito são objeto de intensas críticas, sendo Eugenio Raul Zaffaroni uma de suas vozes mais enfáticas, e que, já no distante ano de 1989, advertia para a perversidade da prática sistema penal, e de modo especial na realidade marginal latinoamericana, cujos fatos seriam como "curto-circuitos" à deslegitimação do discurso jurídicopenal abstrato e distante, e que não conseguiria ocultar a realidade operativa dos sistemas penais (1991. p. 39).

No seminal ensaio de Zaffaroni são mencionados alguns discursos críticos dessa mesma operacionalidade efetiva do sistema penal, dentre os quais o de Michel Foucalt, responsável por sistematizar a noção de que as instituições penais, com a prisão em seu centro, se valeriam de "ilegalismos" para a construção de infrações penais, que recairiam sobre conjuntos da população a que se busca controlar (BARBOSA, 2017. p. 90), sendo essa a função oculta do sistema penal: a da contenção e gestão dos indesejáveis. Constatar esse estado de coisas traz consigo a noção de que o sistema penal poderá sempre ser invocado para finalidades diversas, não reconhecidas pelo discurso oficial (ALTOÉ, 2017. p. 57-58).

Uma outra corrente altamente deslegitimadora do discurso jurídico-penal seria a concepção da cifra oculta da criminalidade, cuja constatação deita suas origens nas constatações de Edwin Sutherland sobre a criminalidade de colarinho branco, que, apesar de vinculada a condutas de elevada danosidade social, praticadas do pessoas de elevados estratos sociais, consistiria em uma área de grande impunidade, onde o comportamento delinquente é, por regra, esquecido (SANTOS, 2000. p. 192-194).

E a constatação social quanto à ausência de reflexos criminalizantes envolvendo condutas delitivas, especialmente em âmbito empresarial, materializa a ideia de cifra oculta da criminalidade, consistente na imensa quantidade de condutas classificadas como crimes que sequer chegariam ao crivo das agências penais, mesmo ocorrendo em grande escala (KAZMIERCZAK, 2010. p. 36). Correntes críticas da criminologia, diante desse cenário, inferem que "a efetiva criminalização é um fato raro e excepcional" (HULSMAN, 2004. p. 49), que recai, de modo preferencial, sobre os "alvos privilegiados" (WACQUANT, 2007. p. 331-349), aqui vistos como sendo pessoas de baixa renda, pouca escolaridade e de cor negra e parda.

Todavia, para Zaffaroni, a função deslegitimante mais importante e irreversível do discurso jurídico-penal seria aquela exercida pela fenomenologia e o interacionismo simbólico (1991. p. 60), da qual Howard Becker e sua teoria da rotulação (etiquetamento), consistiria no 
maior expoente. Essa corrente criminológica direciona os seus estudos aos processos de criminalização, produzidos por sociedades e suas instituições, por meio da atribuição de rótulos aos praticantes de comportamentos não desejados por aquela sociedade, e que serão um estigma para seus comportamentos futuros (ANITUA, 2008. p. 588-592). Diante dessa grande ruptura com preceitos criminológicos etiológicas, seria este o golpe deslegitimador mais forte recebido pelo sistema penal, “do qual o discurso jurídico-penal não mais poderá recuperar-se, a não ser fechando-se hermeticamente a qualquer dado de realidade, por menor que seja, isto é, estruturando-se como um delírio social” (ZAFFARONI, 1991. p. 61).

Sendo assim, as conclusões de Zaffaroni, extraídas do discurso criminológico crítico e, especialmente, da realidade operacional dos sistemas penais na américa latina, mesmo que datadas de mais de 30 (trinta) anos atrás, chamam a atenção para o grande vazio existente entre a ciência (e a realidade) social e o discurso jurídico-penal (1991. p. 93), e a conseguinte deslegitimação deste último. No paradoxo de uma sociedade humana que nada teria de humana, como adverte Luís Carlos Valois, o Direito segue ao largo disso tudo, criando doutrinas, princípios e regras para seu consumo próprio, não tendo a ciência do direito, mesmo revestida das melhores intenções, logrado em diminuir o autoritarismo inerente à prática punitiva (2019. p. 158-160).

\section{O PAPEL DO DISCURSO JURÍDICO-PENAL DIANTE DE UM SISTEMA PENAL DESLEGITIMADO: REDUÇÃO DE DANOS?}

Às graves constatações de Zaffaroni, ao término dos anos 80, que já indicavam uma irreversível deslegitimação do sistema penal, em diagnóstico da operacionalidade real das agências punitivas da américa latina, se soma o reconhecimento pelo Supremo Tribunal Federal, em 2015, em decisão liminar proferida na arguição de descumprimento de preceito fundamental (ADPF) $347^{4}$, de que o sistema penitenciário brasileiro seria um quadro de violação massiva e persistente de direitos fundamentais, proveniente das falhas estruturais e da falência das políticas públicas nesse âmbito, caracterizando-se um "estado de coisas inconstitucional". 5

\footnotetext{
${ }^{4}$ BRASIL. Supremo Tribunal Federal. ADPF 347 MC. Relator: Ministro Marco Aurélio. Tribunal Pleno, julgado em 09.09.2015.

${ }^{5}$ Trata-se de conceito novo na dinâmica do STF, importado da jurisprudência da Corte Constitucional da Colômbia, nos processos de tutela números T-137001 e T-143950, que se caracteriza "pela vulnerabilidade massiva e generalizada de vários direitos constitucionais e que atingem número significativo de pessoas, e pela omissão das autoridades que deveriam agir para fazer cessar as violações e adotar medidas para garantir e reparar os direitos
} 
E esse cenário de permanente violência e massiva ofensa de direitos fundamentais, especialmente sentido pela realidade carcerária brasileira, torna necessária a reorientação do discurso jurídico-penal, nos moldes traçados por Zaffaroni em seu ensaio, onde se sustenta a necessidade de construção de um novo discurso jurídico-penal, adequado às mazelas do realismo marginal latino-americano (e notadamente o brasileiro), e que aceite e reconheça a deslegitimação do exercício de poder pelo sistema penal, e que busque uma posição estratégica de pautar as decisões proferidas por órgãos judiciais, tendo como objetivo a redução da violência de pautar as decisões proferidas por órgãos judiciais, tendo como objetivo a redução da violência pulsante em meio à operacionalidade do sistema (1991. p. 172).

O discurso jurídico penal, nesse cenário, deve atuar com vistas reduzir a incidência irrestrita do poder punitivo, ao mesmo tempo em que se utiliza de mecanismos do próprio discurso jurídico-penal, modulando-os de forma a reduzir ao máximo a incidência dos sistema penal, que é, por excelência: seletivo, produtor de ilegalidade, rotulador de novos "criminosos" e catalisador da violência. Em perspicaz metáfora, a função do direito penal é a de um dique de contenção do poder punitivo, mas que, simultaneamente, obstaculiza a contenção de uma quantidade tão enorme de água que provoque o seu rompimento, devendo, assim, operar seletivamente, filtrando somente as águas mais sujas e reduzindo sua turbulência, por meio de um complexo de sistema de comportas, que impeçam a perfuração de qualquer delas (BRODT, 2010. p. 102).

A proposta de Zaffaroni objetiva, assim, construir um discurso jurídico-penal que reconheça a deslegitimação do sistema penal que se atesta pela sua realidade operacional, adotando, por outro lado, as cautelas para não relegitimar o mesmo sistema. A legitimação que deve ser buscada pelo discurso jurídico-penal é a atuação da agência judicial, a decisão judicial e o exercício do poder dos juristas, que devem se contrapor ao exercício dos demais poderes exercidos pelas agências do sistema penal, funcionando como um mecanismo de redução de danos (FERRAZ, 2018).

O reconhecimento da deslegitimação do exercício de poder do sistema penal pode indicar, à primeira vista, que a sua abolição seria uma inferência lógica. No entanto, para

violados". In: TAQUARY, Eneida Orbage De Britto e COSTA, Wangle Samuel Leão. O Diálogo entre Colômbia e Brasil sobre o "estado de coisas inconstitucional". Revista de la Secretaría del Tribunal Permanente de Revisión. Asunción. v. 7, n. 13, p. 193-212. Mar. 2019. Disponível em: http://scielo.iics.una.py/pdf/rstpr/v7n13/23047887-rstpr-7-13-193.pdf Acesso: 11 abr. 2020. 
Zaffaroni, a despeito da evidente deslegitimação, o sistema penal mantém por ser um fato de poder, tal como a guerra, igualmente deslegitimada, mas que se mantém em razão da relação de poder que lhe é ínsita. E o exercício do poder não é pautado pela racionalidade, pois, caso o fosse, não existiria espaço tanto ao sistema penal como para a guerra, razão pela qual o discurso jurídico-penal, em meio a esse estado de coisas, deve assumir um papel análogo ao exercido pelo discurso humanitário em relação à guerra, com a tentativa de controle um fato de poder que não pode suprimir (1991. p. 195-201).

Deste modo, a proposta constante no ensaio do jurista argentino traz elementos de um abolicionismo utópico, escalonado em um enfrentamento racional do ato de poder em que consiste o sistema penal, buscando reduzir-lhe a violência, para, ao fim, suprimi-lo, em alinhamento com conceitos de Thomas Mathiesen, o "estrategista do abolicionismo", que sugere a noção das unfinished policies, pois, ao se constatar o abolicionismo penal efetivo como uma reforma a longo prazo, é necessária uma ação política inacabada, que, a curto prazo, impõe a adoção de um posicionamento sempre antagônico à ampliação do poder dos sistemas penais (1986. p. 81-82).

\section{A CONTRIbUiÇÃo dA TEORIA DO QUARTO PODER DE SCHÜNEMANN PARA O CONTROLE RACIONAL DO DIREITO PENAL DESLEGITIMADO}

Um papel central, nesse dique de contenção do avanço do estado policialesco da violência operacional de sistemas penas recai sobre o saber produzido pela academia, denominada "agência de reprodução ideológica" por Zaffaroni, que deveria estar sempre mais avançado em relação ao padrão exercidos pelos órgãos judiciais, o que seria fundamental para viabilizar um "estímulo à jurisprudência". Deste modo, incumbiria à academia o exercício de uma crítica permanente das agências judiciais e das políticas (legislativas), pois somente assim agindo é que as "agências de reprodução ideológica" poderiam se transmudar em agências de dinamização ideológica do sistema penal (ZAFFARONI, 1991. p. 237).

Sem descuidar das críticas contundentes feitas pelo penalista argentino sobre a disfuncionalidade muitas vezes existente entre o saber aplicado nos países centrais em relação realidade dos sistemas penais latino-americanos, o papel por ele projetado para o saber produzido pelas academia (agência de reprodução ideológica) de controle e crítica dos órgãos 
judiciais, com vistas a lhes conferir progresso e diminuição da violência, guarda uma aparenta ser complementada pela teoria do "quarto poder" 6 desenvolvida mais recentemente pelo alemão Bernd Schünemann, em relação à função da dogmática e do saber acadêmico em matéria penal.

Para Schünemann, a relação entre e a dogmática e as práticas jurídicas deveria ser pautada pela premissa de que a jurisprudência também exerce uma espécie de dogmática autoritativa, por meio da transformação da razão pura (teorética) em razão prática, razão pela qual deveria estar ela pautada pela mesma racionalidade empregada pelo cientista do direito, apenas com o acréscimo de força vinculante que escapa ao teórico (2018. p. 89).

Com o estabelecimento dessa premissa, Schünemann desenvolve o conceito da teoria do "quarto poder" atribuído à dogmática em relação à prática dos órgãos judiciais:

\begin{abstract}
Disso resultam a possibilidade e a tarefa da dogmática - praticada por cientistas - de controle intelectual da dogmática praticada por juízes. Por essa razão, designei a ciência jurídica como uma forma de quarto poder, que não possui literalmente poder algum (que não exerce domínio) e justamente por isso deve responder a quase indecifrável pergunta: "quis custodiet ipsos custodientes"? Apenas assim é possível obter uma quebra do regresso ao infinito de controle que se teria em um Estado de Direito com divisão de poderes. (2018. p. 90)
\end{abstract}

E como resultado da função do quarto poder como uma resposta ao brocardo latino constante em uma das sátiras do poeta romano Juvenal, cotidianamente reutilizada para o questionamento de poderes constituídos, sustenta Schünemann que uma jurisprudência que não se abre para a crítica científica não passaria de uma "justiça do cádi"7 que não deveria existir em um Estado Democrático de Direito, pois apenas por meio do controle científico exercido pelo "quarto poder" é que o poder judicial, munido de uma precária legitimidade democrática, se justificaria e se tornaria suportável (SCHÜNEMANN, 2019. p. 76).

De forma a complementar e enfatizar a importância da teoria do "quarto poder", como instrumento para que o saber científico delimite a incidência irrestrita e irracional do

\footnotetext{
${ }^{6}$ A primeira utilização do termo remonta à obra comemorativa dos 70 anos do dogmata Claus Roxin: SCHÜNEMANN, Bernd. Strafrechtsdogmatik als Wissenschaft, in: Schünemann et alii (coords.), Festschrift für Roxin, Berlin/New York, 2001, p. 1 e ss., e incorporada à realidade brasileira em tradução e coordenação feitas no ano de 2018, por Adriano Teixeira, de texto originalmente publicado em 2016 pelo autor alemão:

SCHÜNEMANN, Bernd. Dez teses sobre a relação dogmática penal com a política criminal e com a prática do sistema penal. In: Direito penal racionalidade e dogmática: sobre os limites invioláveis do direito penal e o papel da ciência jurídica. Coordenação e tradução: Adriano Teixeira. São Paulo: Marcial Pons, 2018 - p. 87-93

7 Trata-se de citação de Max Weber, que se utiliza do termo "justiça do cádi para se referir a manifestações jurídicas irracionalmente materiais, sendo o Cádi o juiz muçulmano. Conforme: CASTRO, Alexander de. Max Weber e a história do direito: Fundamentos empíricos e historiográficos da sociologia jurídica weberiana. Revista Brasileira de Estudos Políticos. Belo Horizonte. n. 112. jan./jun. 2016 - p. 33
} 
poder punitivo, Luís Greco, em artigo publicado em homenagem aos 70 (setenta) anos de Schünemann, destaca que a ciência jurídica teria a função de colocar à prova os atos judiciais e legislativos, para rechaçar aqueles que consistam em simples atos de poder, na medida em que, sempre que juízes e legisladores possuem liberdade plena para formular suas pretensões de juridicidade, sem temer a vigilância crítica de uma instância munida de independência, haveria um caminho amplo para a tomada de decisões desprovidas de qualquer respaldo. Assim, segundo Greco, "a ciência e a dogmática do direito, exercidas por professores enquanto professores, devem desnudar o que é um ato nu der poder" (GRECO, 2019. p. 29).

Referindo expressamente ao quarto poder, nos termos em que desenvolvido por Bernd Schünemann, afirma o autor:

\footnotetext{
É a ciência do direito que, no seu cotidiano, coloca à prova a pretensão, implicitamente existente, de que esses atos sejam mais do que simples atos de poder. A ciência do direito, portanto, atua como um "quarto poder" impotente, vigia se as atividades dos outros três poderes potentes se sustentam em razões. Ela não pratica essa vigilância por meio força corporal, senão racional, a fim de que essas razões também suportem seus resultados. Ela obriga o poderoso a prestar contas de suas decisões e o denuncia quando as razões indicadas por ele, na verdade, são uma racionalização insincera. A ciência do direito é, portanto, a ciência da distinção entre direito e poder. (2019. p. 26)
}

Com o desenvolvimento da referida teoria, se verifica um pertinente diálogo entre o "quarto poder" que incumbe à academia, como sustentam Schünemann e Greco e o papel projetado por Zaffaroni, na realidade marginal latino-americana, às "agências de reprodução ideológica", como denomina as universidades e o saber científico, no sentido de que sejam fonte de mudança e de crítica permanente da produção jurisprudencial, especialmente em matéria penal, para que com isso existam meios de reduzir a violência de um sistema deslegitimado em razão da suas práticas concretas, já acima antevistas.

Um discurso jurídico-penal racional e ciente de suas funções, quando erigido à relevante de função de detentor do "quarto poder", que se exerce pela racionalidade e não pela imposição, pode ser um relevante agente de redução de danos, mediante redução da violência do sistema penal, para atenuar a sua intervenção, consistindo, ainda, "na forma mais prática e efetiva de se agir sobre os homens e as instituições, modificando normas e inaugurando uma ética voltada para a vida" (ZAFFARONI, 1991. p. 225). 


\section{DESAFIOS DA IMPLEMENTAÇÃO DA TEORIA DO QUARTO PODER EM FACE DA REALIDADE DA ACADEMIA BRASILEIRA.}

Mesmo que a implementação de uma teoria que busque conferir racionalidade à atuação dos órgãos judiciais, por meio de um diálogo com o saber acadêmico, aparente ser algo a ser buscado e melhor desenvolvido, é necessário compreender todo o contexto que circunda a teoria do "quarto poder" e o seu local de surgimento (realidade acadêmica alemã), que destoa da realidade brasileira, evitando, assim, uma incorporação de um instituto formatado para uma realidade inaplicável à brasileira.

A propósito do uso de estudos comparados, Max Weber (2013. p. 290) há muito advertia que seu objetivo não deveria ser o de buscar por "analogias" ou "paralelos", mas precisamente o oposto, identificar a individualidade de cada desenvolvimento, junto às características que o fizeram concluir de uma forma tão diferente daquela do outro. Feito isso, pode-se então determinar as causas que levaram a essas diferenças. No campo jurídico também há uma consolidada crítica acerca dos "transplantes jurídicos", metáfora usada para a definição da transposição de institutos e normas jurídicas, concebidas para determinada realidade jurídica, para uma outra, completamente diversa em sua essência. Deste modo, é necessário que a metáfora do transplante seja convolada na "tradução jurídica", e que ao se preocupar com as singularidades de determinado instituto ou teoria jurídica no seu meio de concepção, possibilita a sua incorporação a um outro ordenamento jurídico. ${ }^{8}$

Firmadas essas premissas, é pertinente examinar, ainda que de forma introdutória, o contexto existente e que viabilizou a concepção da teoria do "quarto poder", e que é o da realidade acadêmica da Alemanha, tomando em vista que tanto Bernd Schünemann, o precursor, como Luís Greco, são profícuos professores, com ampla atuação acadêmica no país germânico ${ }^{9}$, para que possam ser traçados os desafios para a implementação efetiva da teoria no contexto brasileiro.

\footnotetext{
${ }^{8}$ Sobre as críticas e diferenças entre os "transplantes jurídicos" e "traduções jurídicas", confira-se a dissertação de Guilherme Lucchesi, que aborda de forma exauriente o indevido transplante do instituto da cegueira deliberada ao ordenamento jurídico brasileiro: LUCCHESI, Guilherme Brenner. A punição da culpa a título de dolo: o problema da chamada "cegueira deliberada. Dissertação de Doutorado. UFPR. Setor de Ciências Jurídicas. Programa de Pós-Graduação em Direito - p. 178-187. Disponível em: https://www.acervodigital.ufpr.br/handle/1884/49523 Acesso em 11 abr. 2020

${ }^{9}$ Bernd Schünemann é Professor Emérito de Direiteo Penal, Direito Processual Penal e Filosofia do Direito da Universidade Ludwig-Maximilian, de Munique, ao passo que Luís Greco é Professor catedrático de direito penal, direito processual penal, direito penal estrangeiro e teoria da direito penal na universidade de Humboldt, de Berlim, tendo sido orientando de Schünemann em sua habilitação.
} 
No artigo já referido, Greco indica que um elemento fundante da teoria do "quarto poder" a ser exercido pela ciência jurídica, seria o "ambiente institucional" existente na Alemanha, que, com seus institutos, cátedras e todo o aparato funcional (secretários, colaboradores científicos e estudantis), assegura uma "proteção institucional" ao cientista do direito, que fica obrigado ao ideal de produzir ciência jurídica independente, não sendo constrangido institucionalmente na realização de críticas ao trabalho de operadores do direito, como juízes e legisladores (GRECO, 2019. p. 28-29).

Luís Greco, brasileiro e graduado em direito pela Universidade Federal do Rio de Janeiro, apesar do desenvolvimento de sua trajetória acadêmica posterior ter ocorrido na Alemanha, constrói a ideia da essencialidade do ambiente institucional alemão, mediante comparação com modelos adotados outros países, cujas Faculdades de Direito seriam, frequentemente, nada mais do que "prédios com salas de aula e, eventualmente, com uma biblioteca e uma cafeteria", nas quais as aulas seriam dadas por práticos, fazendo, assim, com que seus cientistas fossem, em primeiro lugar, advogados ou juízes, carecendo da indispensável proteção institucional existente na academia alemã, pois pensariam duas vezes antes de tecerem críticas, sobretudo, quanto ao teor das decisões judiciais (2019. p. 28-29).

As raízes brasileiras do referido autor indicam que, ainda que não exista menção expressa no texto nesse sentido, de que o cenário por ele descrito, se adequa à realidade do ensino da pesquisa em direito no Brasil, cuja crítica mais contundente se centra no fato de o ensino ensino jurídico estar "fundamentalmente baseado na transmissão dos resultados da prática jurídica de advogados, juízes, promotores e procuradores, e não em uma produção acadêmica desenvolvida segundo critérios de pesquisa científica” (NOBRE, 2009).

Diante deste cenário, a produção científica em direito, em âmbito brasileiro, resta comprometida, pois a ciência é diametralmente oposta à prática judiciária exercida por juízes, advogados e demais membros dessa burocracia judicial, fazendo com que o ensino jurídico privilegie a lógica automatizada que rege os pareceres destes atores judiciais, em detrimento de fomentar e dar o suporte necessário ao desenvolvimento de uma verdadeira produção científica em direito (BARROS, 2018. p. 33).

A lógica parecerista e o ensino e pesquisa levados a cabo com a metodologia da atuação prática de agentes da burocracia judicial, característicos do ensino jurídico no Brasil, 
aparentam ser o maior desafio para que se implemente a "teoria do quarto poder", na forma como propõem Schünemann e Greco, em nossa realidade, pois é somente com uma ciência jurídica independente, que não paute sua pesquisa pela manutenção do status quo, principalmente, pelos órgãos judiciais, que se viabilizará a necessária permanente crítica, para enfrentar a violência de nosso sistema penal.

É só por meio do avanço de uma pesquisa científica, que trace limites claros com a prática judicial, justamente para que se viabilize a crítica e o avanço desta última, que se pode falar em uma verdadeira incorporação da "teoria do quarto poder" em nossa realidade, o que se faz ainda mais urgente diante do cenário da realidade operacional de nossos sistemas penais, reservando, assim, ao discurso jurídico-penal, relevante papel, e que se pretende ultrapassar o campo meramente teórico, através da contenção da violência sistêmica das agências penais.

\section{CONCLUSÃO}

Uma análise que não seja meramente conceitual da teoria do quarto poder, concebida por Bernd Schünemann, mas que leve em consideração, para além disso, os fatores do ambiente social acadêmico em que a teoria foi gerida, acarreta a conclusão de que, muito embora seja muito válida e promissora a ideia de que a ciência jurídica deve funcionar como local de constante crítica e análise da prática jurídica que desempenham juízes e legisladores, sua incorporação à realidade brasileira, exige, necessariamente, o implemento da pesquisa e do ensino jurídicos no Brasil.

É preciso romper com a noção de que o ensino jurídico deve buscar apenas formar e perpetuar conhecimentos advindos da prática jurídica, pois a manutenção desse estado de coisas tolhe a possibilidade de a ciência jurídica brasileira manter uma postura de crítica contundente da prática judiciária e da atuação do legislador, que é ainda mais necessária na incidência do direito penal e da aplicação de penas, naquelas excepcionais hipóteses em que se rompe o enorme campo da cifra oculta da criminalidade.

Às relevantes constatações feitas por Eugenio Raul Zaffaroni acerca da realidade dos sistemas penais latino-americanos, já em 1989, pautados por uma incontrolável violência, se soma o fato de que o Supremo Tribunal Federal ter reconhecido, em 2015, por ocasião de medida liminar na ADPF 347, que o sistema penitenciário brasileiro proporciona um "estado 
de coisas inconstitucional" àqueles que são alcançados pelo mesmo, sendo ele ambiente de massivas violações de direitos humanos. Ou seja, mesmo passados mais de 30 (trinta) anos das denúncias de Zaffaroni, a realidade operacional de nossos sistemas penais aparente ser a mesma, ou ainda mais agravada.

Nesse contexto é que se impõe o fomento de um discurso jurídico-penal produzido nas academias de direito que tome em consideração a manifesta deslegitimação de nosso sistema penal, e que impõe ao pesquisador em direito penal um desafio dúplice: produzir um discurso que seja o mais redutor possível dos tantos efeitos danosos decorrentes da realidade de nossos sistemas penais, ao mesmo tempo em que se procure fazer com que seu discurso transcenda os bancos da faculdade e possa auxiliar na formação dos órgãos jurisdicionais, evidenciando, assim, o grande potencial da incorporação dos conceitos da teoria do quarto poder, recentemente tornada acessível à realidade acadêmica brasileira, e que necessita de um grande esforço conjunto, pela aprimoração do ensino e da ciência jurídica, para que seja efetivamente praticável dentro de nossa realidade brasileira.

\section{REFERÊNCIAS}

ALTOÉ, Rafael. Política Criminal e Direitos Fundamentais - Novas tendências penais, força normativa e horizonte das liberdades individuais na pós-modernidade. Belo Horizonte, Editora D’Plácido, 2017

ANITUA, Gabriel Ignacio. Histórias dos pensamentos criminológicos. Tradução: Sérgio Lamarão. Rio de Janeiro: Revan: Instituto Carioca de Criminologia, 2008.

BARBOSA, Antônio Rafael. 40 anos do Vigiar e Punir: Um rumor em tempos incompatíveis. EMAS: Revista de Estudos de Conflito e Controle Social. DILEMAS - Ed. Especial 2, 2017

BARROS, Marco Antonio Loschiavo Leme de. BARROS, Matheus de. Os Desafios e os novos caminhos da pesquisa em direito no Brasil. Revista de Estudos Empíricos em Direito, vol. 5, n. 1, mar 2018. Disponível em:

<https://revistareed.emnuvens.com.br/reed/issue/view/11> Acesso: 11.04.2020, às 10h30min

BRASIL. Supremo Tribunal Federal. ADPF 347 MC. Relator: Ministro Marco Aurélio. Tribunal Pleno, julgado em 09.09.2015.

BRODT, Luiz Augusto Sanzo. O Direito Penal sob a Perspectiva Funcional Redutora de Eugenio Raul Zaffaroni. Revista Brasileira de Estudos Políticos, Belo Horizonte, n. 101, jul./dez. 2010 
CASTRO, Alexander de. Max Weber e a história do direito: Fundamentos empíricos e historiográficos da sociologia jurídica weberiana. Revista Brasileira de Estudos Políticos. Belo Horizonte. n. 112. jan./jun. 2016

FELDENS, Luciano. Direitos Fundamentais e direito penal: a constituição penal. 2. ed. Porto Alegre: Livraria do Advogado Editora, 2012

FERRAJOLI, Luigi. Direito e razão: teoria do garantismo penal. Tradução: Juarez Tavares [et. al.] São Paulo: Editora Revista dos Tribunais, 2002

FERRAZ, Hamilton Gonçalves. Direito Penal sem pena? Uma Introdução à teoria agnóstica da pena. Revista Brasileira de Ciências Criminais, vol 148 (outubro de 2018).

GIACOMOLLI, Nereu José. Função garantista do princípio da legalidade. Revista Iberoamericana de Ciências Penais. Porto Alegre, maio-agosto, 2000

GRECO, Luís. Dogmática e Ciência do Direito Penal. In. As razões do direito penal. Quadro Estudos. Tradução e Organização: Eduardo Viana [et. al.] São Paulo: Marcial Pons, 2019.

JUVENAL, n.d., 'D. lunii luvenalis Satiraes 345'. Disponível em: <http://www.thelatinlibrary.com/juvenal/6.shtml> Acesso em 10.04.2020, às 21h50min

HULSMAN, Louk. Alternativas à justiça criminal. in PASSETI, Edson. Curso livre de abolicionismo penal - Rio de Janeiro: Revan, 2004

KAZMIERCZAK, Luiz Fernando. Conceito de Delito à Luz da Constituição Federal de 1988. In. Argumenta: Revista do Programa de Mestrado em Ciência Jurídica, da FUNDINOPI - UENP / Centro de Pesquisa e Pós-Graduação (CPEPG), Conselho de Pesquisa e PósGraduação (CONPESQ), Faculdade Estadual de Direito do Norte Pioneiro. n. 11 (julhodezembro). Jacarezinho, 2009. Disponível em:

$<$ http://seer.uenp.edu.br/index.php/argumenta/article/view/140> Acesso em 10.04.2020, às $21 \mathrm{~h} 50 \mathrm{~min}$

KAZMIERCZAK, Luiz Fernando. Direito Penal Constitucional e Exclusão Social. Porto Alegre: Núria Fabris Ed., 2010

LUCCHESI, Guilherme Brenner. A punição da culpa a título de dolo: o problema da chamada "cegueira deliberada. Dissertação de Doutorado. UFPR. Setor de Ciências Jurídicas. Programa de Pós-Graduação em Direito - p. 178-187. Disponível em: <https://www.acervodigital.ufpr.br/handle/1884/49523> Acesso em 11.04.2020, às 08h30min

MARTÍN, Luiz Gracia. O Horizonte do Finalismo e o Direito Penal do Inimigo. Tradução: Érika Mendes de Carvalho e Luiz Regis Prado. São Paulo: Editora Revista dos Tribunais, 2007

MATHIESEN, Thomas. The politics of abolition. In. Contemporary Crises 10 (1986) 
NOBRE, Marcos. Apontamentos sobre a pesquisa em Direito no Brasil. FGV DIREITO SP Cadernos Direito GV, 2009. Disponível em:

<https://bibliotecadigital.fgv.br/dspace/handle/10438/2779> Acesso em 11.04.2020, às 09h30min

PRADO, Luiz Regis. Bem jurídico-penal e constituição. $3^{\mathrm{a}}$ ed. rev. atual. e ampl. - São Paulo: Editora Revista dos Tribunais, 2003

ROCHA, Alvaro Oxley. Direito Penal e Direitos Fundamentais na Constituição Brasileira. In. Direito Penal e Constituição: diálogos entre Brasil e Portugal. Porto Alegre: Boutique Jurídica, 2018

ROUSSEAU, Jean Jacques. The social contract \& Discourses by Jean Jean Jacques Rousseau. Book II, Chapter V. The Right of Life and Death. Trad.: COLE, G. D. H. Disponível em: < http://www.dominiopublico.gov.br/pesquisa/PesquisaObraForm.jsp> Acesso em 11.04.2020, às 10h00min

SANTOS, Cláudia Cruz. O Crime de Colarinho Branco, a (des)igualdade e o problema dos modelos de controlo. In. Temas de Direito Penal Econômico. Organizador: Roberto Podval. São Paulo: Editora Revista dos Tribunais 2000 -

SCHÜNEMANN, Bernd. Dez teses sobre a relação dogmática penal com a política criminal e com a prática do sistema penal. In: Direito penal racionalidade e dogmática: sobre os limites invioláveis do direito penal e o papel da ciência jurídica. Coordenação e tradução: Adriano Teixeira. São Paulo: Marcial Pons, 2018

SCHÜNEMANN, Bernd. La misión o tarea de la dogmática jurídica (penal) como cuarto poder. In: El Derecho Penal em El Estado Democrático de Derecho y el irrenunciable nível de racionalidad de su dogmática. Traducción; CAÑADILLAS, Raquel Roso [et. al]. Colección Ciencias Penales. Madrid: Reus Editorial, 2019 - p. 76

SHECAIRA, Sérgio Salomão. Criminologia. $6^{\text {a }}$ ed. rev. e atual. - São Paulo: Editora, Revista dos Tribunais, 2014

TAQUARY, Eneida Orbage De Britto e COSTA, Wangle Samuel Leão. O Diálogo entre Colômbia e Brasil sobre o "estado de coisas inconstitucional". Revista de la Secretaría del Tribunal Permanente de Revisión. Asunción. v. 7, n. 13, p. 193-212. Mar. 2019. Disponível em: <http://scielo.iics.una.py/pdf/rstpr/v7n13/2304-7887-rstpr-7-13-193.pdf > Acesso: 11.04.2020, às 10h00min

VALOIS, Luís Carlos. Processo de execução penal e o estado de coisas inconstitucional. Belo Horizonte: Editora D’Plácido, 2019

WACQUANT, Loïc. Punir os pobres: a nova gestão da miséria nos Estados Unidos [A onda punitiva]. Tradução: Sérgio Lamarão. $3^{\mathrm{a}}$ ed. rev. e ampl. Rio de Janeiro: Revan, 2007

WALDRON, Jeremy. A Dignidade da Legislação. Tradução: Luís Carlos Borges. São Paulo: 
Martins Fontes, 2003

WEBER, Max. The Agrarian Sociology of Ancient Civilizations. Tradução: R.I. Frank. Londres: Verso, 2013 (Ebook) - p. 290. Disponível em:

$<$ https://archive.org/details/max_weber_the_agrarian_sociology_of_ancient_civilizations/pag e/n1/mode/2up/search/comparative+study> Acesso em 11.04.2020, às 08h30min

ZAFFARONI, Eugenio Raul. Em busca das penas perdidas: a perda da legitimidade do sistema penal. Rio de Janeiro, Revan, 1991 